\title{
Revisiting Natural Radiation in Itacaré and Guarapari Beaches
}

\author{
M. A. G. SILVEIRA ${ }^{1 *}$, J. M. OLIVEIRA ${ }^{1}$, V. A. P. AGUIAR ${ }^{2}$, N. H. MEDINA ${ }^{2}$ \\ ${ }^{1}$ Centro Universitário FEI, S.B.C., São Paulo, Brazil \\ ${ }^{2}$ Instituto de Física da USP, S.P., São Paulo, Brazil \\ "Email: marcilei@fei.edu.br
}

Published online: August 08, 2016,

The Author(s) 2016. This article is published with open access at www.chitkara.edu.in/publications

\begin{abstract}
Human beings are constantly exposed to several types of natural radiation. This paper aims to study the total external dose from northwestern Brazilian beach sands. The samples were collected at Prainha in Itacaré, Bahia, and Praia de AreiaPreta in Guarapari, Espírito Santo. Gamma spectrometry is a very useful technique to estimate the effective dose due to naturally occurring radionuclides, such as ${ }^{40} \mathrm{~K}$ and daughters of ${ }^{238} \mathrm{U}$ and ${ }^{232} \mathrm{Th}$. In order to confirm the high activity present in these two regions, the effective dose due to each natural radionuclide was determined. Moreover, the Energy-Dispersive X-Ray Spectroscopy (EDS) microanalysis was used to characterize the soil composition and the minerals responsible for the high activity. In addition, the sand samples were separated in to magnetic and non-magnetic fractions in order to identify the contribution from each portion of the activity. Finally, the radionuclides and their dispersion in those places are consistent with previous studies, indicating effective doses above the world average that is between 0.3 $\mathrm{mSv} /$ year and $1.0 \mathrm{mSv} / \mathrm{year}$.
\end{abstract}

Keywords: Natural radionuclides, beach sands, gamma-ray spectrometry.

\section{INTRODUCTION}

\subsection{Brazilian sands with high radioactivity}

A detailed report on the economic importance of sands and rocks with a high concentration of natural radionuclides in the beach sands of Guarapari, Espirito Santo (ES) and the sands from southern Bahia, where Itacaré beach is located, was published recently. Studies that generated this report, published in reference [2], prove the sending of monazite sand from Guarapari, ES, and

Journal of Nuclear

Physics, Material Sciences, Radiation and Applications Vol-4, No-1, August 2016 pp. 1-11 
Silveira, M.A.G. Oliveira, J.M. Aguiar, V.A.P. Medina, N.H. other municipalities of Rio de Janeiro and Bahia to the United States, France, Germany, and England, between 1890 and 1960. Sometimes this transport was done clandestinely, declared as ordinary sand to fill the ballast of ships. This material, however, was known to be rich in thorium, which was a highly targeted radioactive element in two moments of history: first used for the manufacture of gas lamps, exported to Europe from 1890, and then by the nuclear industry in the late 1940's for development of the atomic bomb. Thorium became a target of international greed after the discovery of what could be produced from it: Uranium-233 $\left({ }^{233} \mathrm{U}\right)$, an element created in the laboratory and used in reactors or atomic bombs [2].

While workers who worked directly with the monazite sands of Guarapari suffered from low salaries and exhausting labor, this sand fed the thirsty American nuclear industry during the Cold War. Bombs with Uranium-233, produced from the extracted thorium in Brazil were tested in 1956, according to files of the US military, representing Brazil's participation in a nuclear war whose access to information until now is restricted [2]. Due to this scene of incredible revelations with radioactive material and government interests involving Brazil, USA and Europe, we have the main motivation for a restudy of the natural radiation sites,Guarapari and Itacaré beaches. In this work we analyzed some samples from Praia Preta, Guarapari (Espirito Santo) and Prainha, Itacaré (Bahia).

\subsection{Natural Radionuclides}

Naturally occurring radionuclides are the major source of radiation exposure to man and consists of both internal and external sources. The most significant internal sources are the radioactive isotopes ${ }^{40} \mathrm{~K}$ and ${ }^{222} \mathrm{Rn}$ which are absorbed through ingestion and inhalation. The external sources are cosmic rays and naturally occurring radioactive isotopes such as ${ }^{40} \mathrm{~K}$, and the isotopes of the series decay of ${ }^{238} \mathrm{U}$ and ${ }^{232} \mathrm{Th}$ [16]. These natural radionuclides can be found in the ground, in building materials, and even in the air. Both internal and external radiation levels may vary with the environmental conditions, for example, the types of rock that constitute landscapes and raw material for building materials. Some regions in Brazil are known for being high background radiation areas (HBRAs), due to the geological formation and geochemical effects [17]. The higher concentration of radionuclides in the Earth's crust is due to minerals, such as monazites and zircons [14]. HBRAs are found at Guarapari, in the coastal region of the State of Espírito Santo and at the Morro do Ferro in the State of Minas Gerais, Brazil [7, 11, 14, 17]. There are several studies indicating HBRA in Guarapari beaches and in the south of Bahia state [1, 3-6, 12, 14].

Natural external radiation includes terrestrial gamma rays, gamma rays from building materials and cosmic radiation. Internal exposure results from 
radionuclides entering the body through ingestion and inhalation of naturally occurring radioactive nuclei in substances such as food, water and air. Gamma radiation from potassium is proceeding from the ${ }^{40} \mathrm{~K}$ isotope, which mainly $\gamma$-decays to the stable nucleus ${ }^{40} \mathrm{Ca}[16]$. The isotope ${ }^{40} \mathrm{~K}$ also decays by electron capture to the stable nucleus ${ }^{40} \mathrm{Ar}$, emitting gamma rays with an energy of $1460 \mathrm{keV}$. The lifetime of this isotope is of the order of 109 years. The isotopes ${ }^{232} \mathrm{Th}$ and ${ }^{238} \mathrm{U}$ are part of two radioactive series where a parent nucleus decays into a daughter nucleus, also radioactive, emitting $\gamma$-rays and $\alpha$ - and $\beta$-particles $[16,9]$.

In most areas of the world the bedrock is covered with soil and sedimentary material. The content of radioactive minerals depends upon the content in the original parent rocks. In soils and sediments, the content of $\mathrm{K}, \mathrm{U}$ and $\mathrm{Th}$ is usually at the same order of magnitude as found in rocks, although somewhat lower due to dynamic effects. In most cases, the uranium decay series is not in radioactive equilibrium in soils whereas thorium decay series often are [8].

It is very important to study radionuclide distribution in soils and sediments to understand the radiological implications in relation to the exposure of the human body to ionizing radiation and the knowledge of which components are found in one specific geographic region [8, 10, 13]. Natural background radiation studies are needed to establish reference levels, especially in areas where the risk of radioactive exposure may be higher.

The present work investigated Brazilian beach sands, in order to analyze the dose from total external natural radiation. We have used gamma-ray spectrometry to measure the activities of the radionuclides ${ }^{40} \mathrm{~K}$ and the elements from the series of ${ }^{238} \mathrm{U}$ and ${ }^{232} \mathrm{Th}$, and the associated effective dose levels in air present in each area studied. The sand samples were magnetically separated and each magnetic fraction was analyzed. In order to determine the mineral species responsible for the high activity found in one specific site, the sand samples were analyzed with a scanning electron microscope, using EnergyDispersive X-Ray Spectroscopy (EDS) microanalysis [10, 13, 17].

\section{METHODOLOGY}

The sand samples were dried in an oven at about $100{ }^{\circ} \mathrm{C}$ for 24 hours, sieved, and stored in sealed plastic containers. The gamma-ray spectrometer used was a $\mathrm{NaI}(\mathrm{Tl})$ scintillator detector placed inside a $7.0 \mathrm{~cm}$ thick Canberra lead shield. The system is coupled with the Genie 2000 software and the UniSpec integrated multichannel analyzer, calibrated with a standard source ${ }^{60} \mathrm{Co}$. The Gamma-radiation system is shown in Figure 1 [10]. For natural radiation
Revisiting Natural

Radiation in Itacaré and Guarapari Beaches 
Silveira, M.A.G. Oliveira, J.M. Aguiar, V.A.P. Medina, N.H.
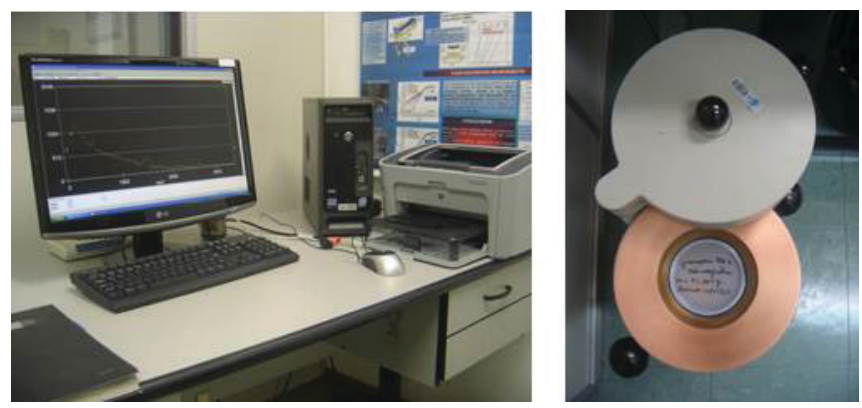

Figure 1: Gamma Radiation System (right) and the Data Acquisition System (left).

studies using high energy gamma-rays, this detection system is very efficient, low cost and allows easy maintenance and operation.

The sample holder is within a lead shield to minimize the capture of background radiation during the data acquisition, which was done over a period of 8 hours. The activity calibration was performed by using the IAEA reference materials: RGU-238, RGTh-232 and RGK-1.

To quantify the natural radiation present in the samples and the effective dose due to external natural radiation, the area under the photo peaks obtained by the gamma-ray acquisition was measured, which corresponds to the number of counts of gamma radiation collected by the $\mathrm{NaI}(\mathrm{Tl})$ detector. Energy discrimination permitted identification of the gamma-radiation emitted by the isotopes ${ }^{40} \mathrm{~K},{ }^{214} \mathrm{Bi}$ daughter of ${ }^{238} \mathrm{U}$ and ${ }^{208} \mathrm{Tl}$, daughter of ${ }^{232} \mathrm{Th}$ [16].

The absorbed gamma-ray dose rates in air, in units of $n G y / h$, were calculated according to Reference [16]:

$$
\boldsymbol{D}=\left[\left(0.462 \mathrm{~A}_{\mathrm{U}}\right)+\left(0.604 \mathrm{~A}_{\mathrm{Th}}\right)+\left(0.0417 \mathrm{~A}_{\mathrm{K}}\right)\right]
$$

where $A_{U}, A_{T h}$ and $A_{K}$ are the activities of ${ }^{238} \mathrm{U},{ }^{232} \mathrm{Th}$ and ${ }^{40} \mathrm{~K}$, respectively, in $\mathrm{Bq} / \mathrm{kg}$.

The absorbed dose is defined as the amount of energy transmitted to a unit of mass under irradiation. To estimate the annual effective dose, the conversion coefficients that must be considered, are the absorbed dose in air to effective dose received by adults equal to $0.7 \mathrm{~Sv} / \mathrm{Gy}$, and the outdoor and indoor occupancy factors, which are equal to 0.8 and 0.2 , respectively. Also, the total external terrestrial radiation was considered. In addition, the annual effective dose is related to the type of radiation that is received. In the case of gamma rays the weight factor is equal to 1 . To sum up, the equivalent dose quantifies the impact of radiation on human beings, given in units of Sv/year, and it can 
be calculated by converting the annual effective dose by a factor which covers the different types of absorption by tissues and organs [16].

$$
\text { Effectivedose }\left[\frac{\boldsymbol{m} \boldsymbol{S} \boldsymbol{v}}{\boldsymbol{a n o}}\right]=\text { Absorbed dose }\left[\frac{\boldsymbol{G} \boldsymbol{y}}{\boldsymbol{h}}\right] * 0.7 * 10^{-6} \frac{\left[\frac{\boldsymbol{S} \boldsymbol{v}}{\boldsymbol{G} \boldsymbol{y}}\right] * 24\left[\frac{\boldsymbol{h}}{1}\right] * 365}{1}\left[\frac{\text { day }}{\text { year }}\right]
$$

Magnetic separation was used to study the sediment composition. Magnetic minerals, such as ilmenite, can be associated with a low concentration of rareearth minerals, giving rise to a higher activity in magnetic fractions of the sediments. Thus, the sand samples from Itacaré, BA and Guarapari, ES, were separated into four fractions using a Frantz Magnetic Barrier Laboratory Separator LB-1: three magnetic fractions, using a magnetic field produced with currents of $0.5 \mathrm{~A}$ (highly magnetic), 1.0 A (magnetic) and 1.5 A (weakly magnetic), side tilt $=15$ degrees, and a non-magnetic fraction.

In addition to scanning electron microscopy, Energy-Dispersive X-Ray (EDS) microanalysis, using a Scanning Electron Microscopy, was performed to help identification of the composition of the sediments in the sample.

\section{RESULTS}

Prior to a more detailed study of the rocky natural radiation associated with the formation of these two beaches the total terrestrial external radiation dose values, for Itacaréwas found to be and 1.97(20) $\mathrm{mSv} / \mathrm{year}$ and for Guarapari beach sand samples, 1.79(15) $\mathrm{mSv} /$ year. Both amounts are above the average world value, established by the International Atomic Energy Agency (IAEA) which is between $0.3 \mathrm{mSv} /$ year to $1.0 \mathrm{mSv} /$ year. After this analysis, a more detailed study to understand which minerals composed the sand samples was done.

In Figure 2, gamma-ray spectra of magnetically separated beach sand samples from Guarapari (left) and Itacaré (right) are shown. In those spectra
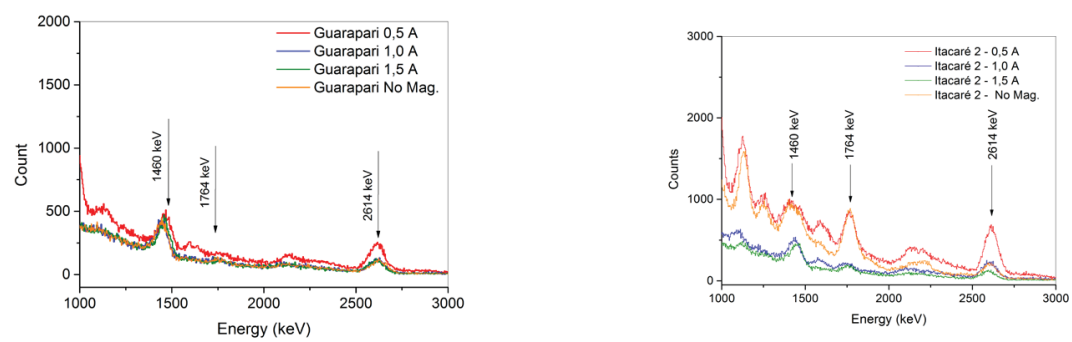

Figure 2: Gamma-ray spectra from magnetically separated Guarapari (left) and Itacare (right) sand samples. 
Silveira, M.A.G. Oliveira, J.M. Aguiar, V.A.P. Medina, N.H.

it is possible to identify the characteristic gamma-ray-peaks of ${ }^{40} \mathrm{~K}$ (1460 $\mathrm{keV}),{ }^{214} \mathrm{Bi}(1764 \mathrm{keV})$ and ${ }^{208} \mathrm{Tl}(2614 \mathrm{keV})$, indicating the presence of ${ }^{40} \mathrm{~K}$ and the radioactive series of ${ }^{238} \mathrm{U}$, and ${ }^{232} \mathrm{Th}$. Different contributions from each radionuclide for each analyzed fraction in Itacaré and Guarapari indicated different rock formations.

In Figure 3. the effective doses classified by isotopic compounds and magnetic fraction from Itacaré (right) and Guarapari (left) beach sands are shown. The results indicate that the sand both locations have high amounts of radionuclides in its composition due to the mineral assembly. The overall sample analysis shows that Itacaré beach sand has a higher uranium concentration than Guarapari beach sand. Guarapari beach is well-known for its high level of activity as the sands are basically composed of monazite mineral, which is correlated with thorium and rare earth elements. Both beach sands presented high activity in magnetic fractions.

For a more detailed analysis, the fractions most representative of radioactive content in the overall sampling were chosen. In Figure 4, it can be seen that the fractions attracted by $0.5 \mathrm{~A}$ (highly magnetic) for Guarapari and $1.0 \mathrm{~A}$ (magnetic) for Itacaré, are the ones that most concentrate the radionuclides, with a greater contribution of ${ }^{232} \mathrm{Th}$ radionuclide for both locations. Also, a small contribution of uranium and potassium to the effective dose in Itacaré beach samples was identified, while in Guarapari there was practically no observation of these isotopes, indicating different rock formation.

For all sand samples from Itacaré 1, 2 and 3, about 89\%, 87\% and $85 \%$ of sand mass was attracted by $0.5 \mathrm{~A}$, respectively, and for the Guarapari samples PRE 1 and PRE 2, 93\% and 97\% of sand mass, respectively, was in the non-magnetic fraction. As could be seen previously, those two fractions have a low concentration of radionuclides, which indicates that radionuclide distribution is not uniform in the sample mass. The different contribution of
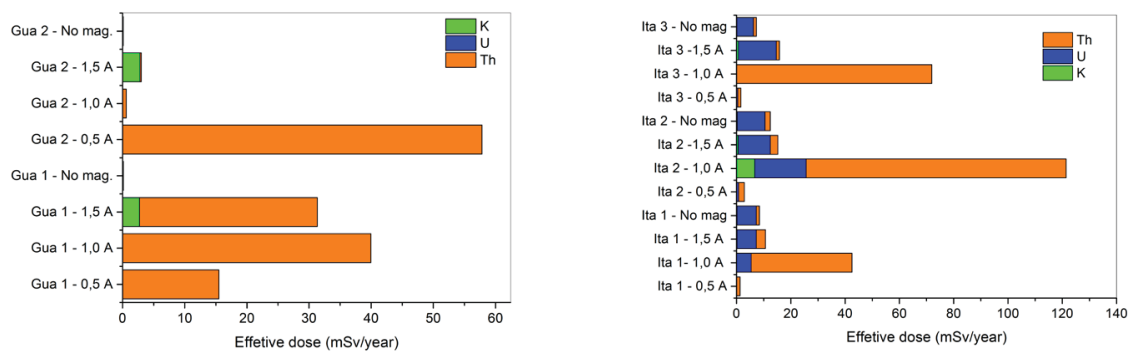

Figure 3: Effective dose divided by isotopic compounds and magnetic fraction from Itacaré (right) and Guarapari (left) beach sand. 


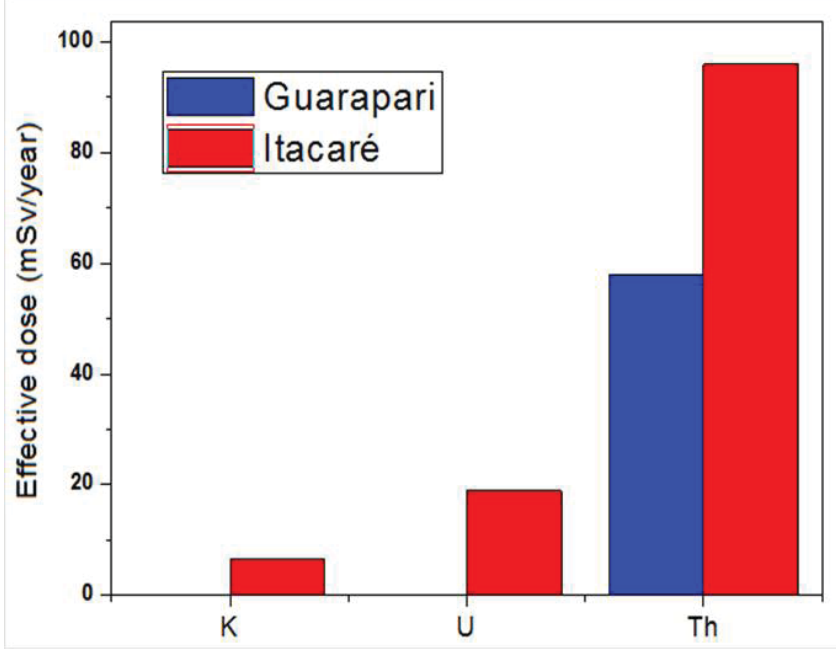

Revisiting Natural

Radiation in Itacaré and Guarapari

Beaches

Figure 4: Effective dose contribution from ${ }^{40} \mathrm{~K},{ }^{238} \mathrm{U}$ and ${ }^{232} \mathrm{Th}$ decay series in Itacaré (1.0 A) and Guarapari $(0.5 \mathrm{~A})$ beach sand samples.

each radionuclide found in each magnetic fraction from Itacaré and Guarapari beach sands confirms different rock formations, which is composed of different mineral concentration. The data concerningthe annual effective dose found for each magnetic and non-magnetic fraction, and its standar deviation, are presented in Tables 1 and 2 for Itacaré and Guarapari beaches, respectively.

Energy-Dispersive X-Ray Spectroscopy (EDS) by Scanning Electron Microscopy (SEM) was used to determine qualitative chemical composition and possible trace of radionuclides in the beach sand samples. Grains of various samples from Itacaré and Guarapari beaches were analyzed, but we will present only the results forItacaré 2 , attracted by $1.0 \mathrm{~A}$, and the non-magnetic fraction; Guarapari PRE2, attracted by $0.5 \mathrm{~A}$, and the non-magnetic fraction. In the case of Guarapari sand samples, due to scattering caused in the beam interaction with heavier elements present in the grain, it was not possible to investigate the details of rock formation. Figure 5. shows the images obtained with the SEM technique from Itacaré 2, 1.0 A: (a) shows the secondary electron micrography, (b), (c) and (d) shows the energy dispersive spectra from points 1,2 and 3, respectively.

It is known from previous studies that finding traces of thorium and uranium in soils containing ilmenite (titanium-iron oxide) is common. According to the EDS technique, observed in Figure 5, a high quantity of ilmenite was found in the magnetic fraction from Itacaré 2 sample $(1.0 \mathrm{~A})$, which is indicative that uranium and thorium are associated with the mineral in the sand samples. 
Silveira, M.A.G. Oliveira, J.M. Aguiar, V.A.P. Medina, N.H.

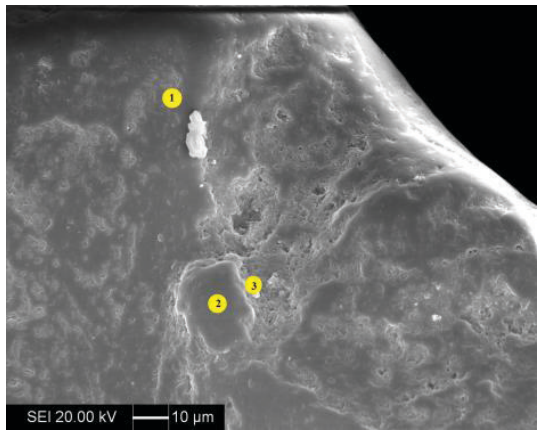

(a)

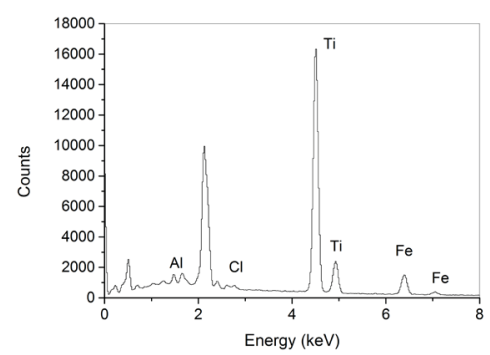

(c)

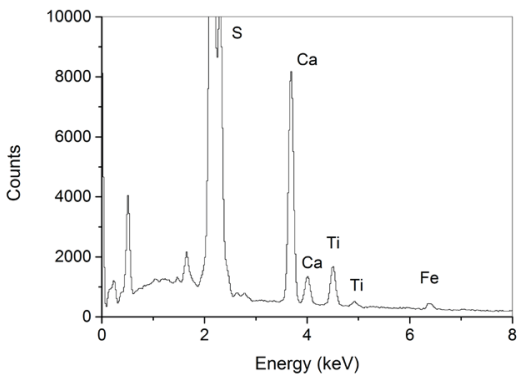

(b)

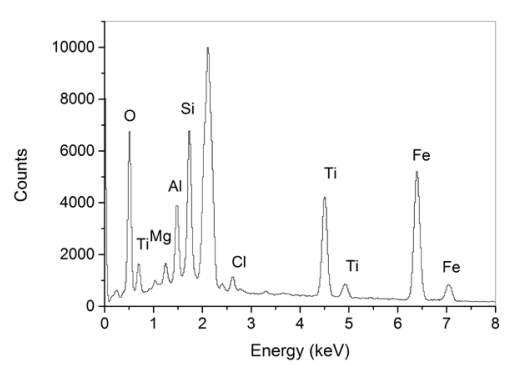

(d)

Figure 5: EDS image from Itacaré 2 sample, 1.0 A: (a) secondary electronmicrography, (b), (c) and (d) energy dispersive spectra from points 1,2 and 3, respectively.

Moreover, aluminum silicate grains were observed. On the other hand, the nonmagnetic fraction is practically composed of quartz and some feldspar [17].

Figure 6 and 7, shows the images obtained with EDS technique from highly magnetic and non-magnetic Guarapari PRE2 fraction, respectively: (a) shows the secondary electron micrography, (b) shows the energy dispersive spectra from point 4 in both figures. All four analyzed points of each sample present the same qualitative composition.

EDS microanalysis of the magnetic fraction from Guarapari PRE2 sample $(0.5 \mathrm{~A})$ presents, basically, clay minerals, in which it is usual to find iron dioxide, and some thorium traces. Besides, the non-magnetic fraction is practically composed of quartz and some other clay minerals, which is seen in Figure 6. Since the titanium concentration is very low compared to the iron concentration, it was not possible to verify the presence of ilmenite, 


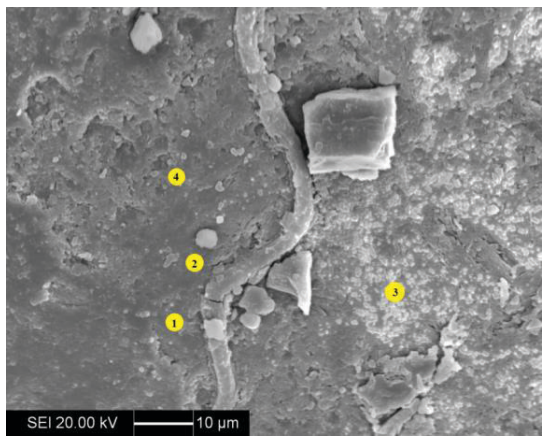

(a)

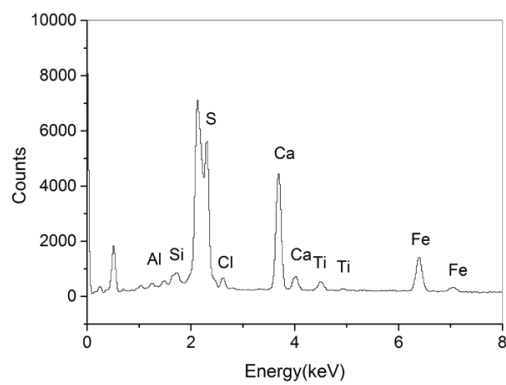

(b)
Revisiting Natural

Radiation in Itacaré and Guarapari

Beaches

Figure 6: EDS image from Guarapari PRE2 highly magnetic fraction: (a) secondary electron micrography, (b) dispersive X-ray spectrum from point 4, where aluminum, calcium, titanium and iron indicate that there may be clay.

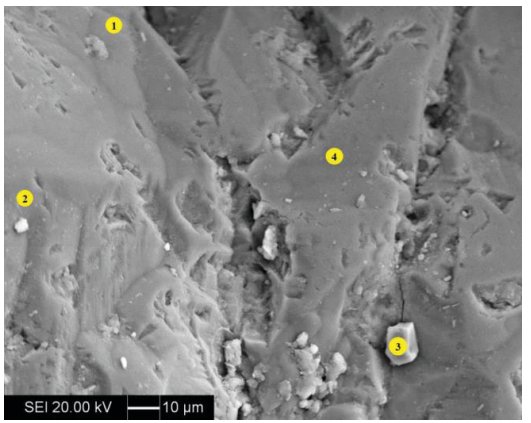

(a)

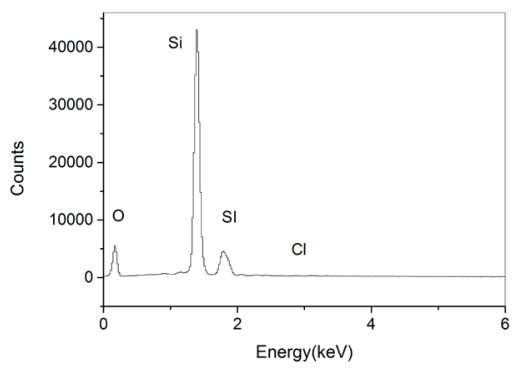

(b)

Figure 7: EDS image from Guarapari PRE2 non-magnetic fraction: (a) secondary electron micrography, (b) dispersive X-ray spectrum from point 4, where silicon indicates that there may be quartz.

confirming different rock formation of both analyzed beaches, since Guarapari samples do not present traces of uranium. Thorium and rare earth elements were not identified in this beach due to technical limitations of the EDS microanalysis, but it is well known that Guarapari sands are basically composed of monazite.

\section{CONCLUSIONS}

This study used gamma spectrometry to study sand samples from two beaches in the northeastern part of Brazil, Itacaré, Bahia state, and Guarapari, Espirito 
Silveira, M.A.G. Oliveira, J.M. Aguiar, V.A.P. Medina, N.H.

Santo state. The results indicate high concentrations of thorium and uranium, and a low concentration of potassium in Itacaré, while in Guarapari the higher contribution for radiation dose is due to thorium. The values found for the effective dose in the population of these regions are 1.97(10) $\mathrm{mSv} /$ year in Itacaré and 1.79(8) mSv/year for Guarapari, both values are higher than the average world value established by the International Atomic Energy Agency (IAEA) that is between $0.3 \mathrm{mSv} / \mathrm{year}$ to $1.0 \mathrm{mSv} / \mathrm{year}$. The microanalysis results indicate the mineral responsible for the high radioactivity in Itacaré is ilmenite, which was found in the magnetic fraction; the same analysis confirms the presence of thorium, that can be correlated to clay minerals, in the magnetic fraction from Guarapari sand samples. Although both beach sands are composed mainly of quartz, the low concentration of radionuclides present in the magnetic fractions determinea different rock formation for each analyzed beach and, consequently, the radioactivity.

\section{ACKNOWLEDGEMENTS}

We are grateful to the Centro Universitário FEI, and the Brazilian funding agencies CNPq, FAPESP, and Wayne Seale for a careful reading of text.

\section{REFERENCES}

[1] A. C. Freitas and A. S. Alencar, Journal of Environmental Radioactivity, 75, No. 2, pp. 211-223, (2004). http://dx.doi.org/10.1016/j.jenvrad.2004.01.002

[2] A GUERRA DE GUARAPARI, http://especiais.gazetaonline.com.br/bomba/, 2015. Access: February, (2016).

[3] A. H. Men T. O. Sanocha, Radiation Protection and Environment, 34, No. 3, pp. 178-184, (2012).

[4] A. Malarica, C. N. Luce, R. Sogni, L. Achilli and S. Fab- bri, Proceedings of the La RadioattivitàAmbientalenelNuovoassettoIsti- tuzionalePiancenza, Bologna and Ravenna, pp. 225-230, (1994).

[5] D. C. Vasconcelos, et al., World Journal of Nuclear Science and Technology, 3, 65-71, (2013). http://dx.doi.org/10.4236/wjnst.2013.32011

[6] D. C. Vasconcelos, et al., Radiation Protection and Environment, 34, No. 3, pp. 178-184, (2012).

[7] F. H. M. Medeiros. Master Thesis, Instituto de Física da USP (2003).

[8] IAEA - National Nuclear Data Center. Available in $\{\mathrm{http}: / /$ www.nndc.bnl.gov/\}. Access: February, 2016.

[9] K. S. Krane, Introduction of Nuclear Physics,John Wiley \& Sons,USA,(1988).

[10] M. A. G. Silveira, N. H. Medina, L. L. Cardoso, Brazilian Journal of Radiation Sciences, 3, p.1/132 - 14, (2015). http://dx.doi.org/10.15392/bjrs.v3i1A 
[11] M. M. Matsumoto, M. A. G. Silveira; N. H. Medina, N. K. Umisedo.AIP Conference Proceedings.Melville, NY, USA: American Institute of Physics, 1034, p. 252-255, (2008). http://dx.doi.org/10.1152/ajpcell.00504.2007

[12] N. Fujinami, T. Koga and H. Morishima, Proceedings of the 10th International Congress of the International Radiation Protection Association, Hiroshima, pp. 1-19, (2000).

[13] P. Chiozzi, V. Pasquale and M. Verdoya, Radiation Measurements, 35, No. 2, 2002, pp. 147- 154. http://dx.doi.org/10.1016/S1350-4487(01)00288-8

[14] R. M. Anjos et al., Marine Geology, 229, 29-43, (2006). http://dx.doi.org/10.1016/j.margeo.2006.03.001

[15] R. Veiga, N. Sanches, R. M. Anjos, K. Macario, et al., Radiation Measurements, 41, No. 2, pp. 189-196, (2006). http://dx.doi.org/10.1016/j.radmeas.2005.05.001

[16] UNSCEAR: Sources and Effects of Ionizing Radiation. United Nations Scientific Committee on the Effects of Atomic Radiation, United Nations, New York, (2000).

[17] V. A. P. Aguiar, M. A. G. Silveira, N. H. Medina, R. H. Moreira, I. J. Sayeg, 17th International Microscopy Congress, Rio de Janeiro, (2010).
Revisiting Natural

Radiation in Itacaré and Guarapari Beaches 